\title{
Policing \& CSWB in Canada: the next 50 years
}

\author{
Norman E. Taylor*
}

By the time the year 2067 rolls around and people celebrate Canada 200, my youngest granddaughter will be approaching the age I am today. Like grandparents everywhere, I often wonder what kind of society she will inherit, shape, and ultimately lead forward for others yet to come. For her and me, this soon-closing Canada 150 year stands as a kind of mustering point for our shared experience spanning over a century of history. As an adolescent long ago, I vividly recall looking ahead to my time. In this themed issue of our Journal, we look ahead to hers.

Of course, the nature and role of policing in a society is but one aspect of that future, but when combined with our broader partners in community safety and well-being, there is much that our vital institution might help to shape. We are fortunate to draw upon an interesting range of perspectives to inform this exercise. The age span between our oldest and youngest contributors to this issue is wide, with 62 years separating their birthdates. One began his policing career the year before I was born. The other is hoping to begin hers very soon. Together and with several others in between, these individuals have generously helped to guide this discussion, and some form the editorial mix of this special issue.

\section{LOOKING AHEAD TO THE PAST}

When our oldest contributor first looked ahead to his policing career, Canada was in the midst of post-war optimism, and the baby boom was at its apex. Immigration levels were high and almost exclusively western European in origin. A police officer was almost certainly a white male, whose near-term ambitions were to support his family, with wages on par with his workmen neighbours but well behind the white collar professionals who lived a few blocks away. Chief of Police (retired) Robert Lunney recalls that his first two decades were guided by a much narrower conception of policing, citing "the obdurate and enduring conception that policing is all about law enforcement, a view still held by a few police practitioners, serving or retired".

For him, one of the most notable and encouraging tides that began to turn in the 1970s and 80s was the introduction and gradual uptake of 'community policing'. He recalls this being impelled by "a cadre of American academics coupled with an emerging generation of college-educated police chiefs" and, as a result in his view, Canadian policing "vaulted ahead to provide a higher and more attentive service to the public" (personal correspondence, October 15,
2017). Two other retired Chiefs of Police, Trevor McCagherty and Barry King, also cite this development as a defining watershed during their tenure. McCagherty observes that this trend became increasingly reflected in the change in language from 'police force' to 'police service'. Prior to this turn, he recalls, "the force had a simple mandate to protect life and property ... prevent and detect crime". As more police services embraced a community policing model, "this enabled the police service to contribute in a greater way to community building." He adds an interesting question, "Did we bite off more than we can chew"(personal correspondence, October 16, 2017)?

King sees this a bit differently. He notes, "Reasonable community expectations were built on trust and respect, the local structure of leadership, base police duties and the citizen's appreciation of being assisted, protected, and supported by their police department, force or service, as it evolved over time." Even in the majority of small to mid-sized police forces, he observes, "beat and patrol officers contributed in large measure to effective relationship building" (personal correspondence, October 26, 2017).

Current Senator and former Commissioner of Police Gwen Boniface describes another pervasive trend that tracked her decades-long career. She offers that, "The biggest change in my career was the impact of technology. It created new crimes and facilitated new accountabilities for police officers" (personal correspondence, October 27, 2017). She and others note the impact of those technological changes on everything from the costs of equipment, to the challenges of continual training, and the still-elusive pursuit of common and reliable standards (Boniface, 2017; King, 2017; Lunney, 2017; McCagherty, 2017).

One mid-term development, perhaps more than any other, seems to have been a common punctuation point for all of these early contributors to our discussion: the 1982 introduction of the Canadian Charter of Rights and Freedoms, and of course, much of the jurisprudence that has followed in its wake. King observes, "Once royal assent was received we faced a significant training curve, and the creation and adoption of new policies and procedures which required a large investment in time and training for all staff." He notes that over the subsequent years of his career, police members at all levels came to discover that many new terms and definitions were shaping their vocabulary, such as "accountability, rights, due process, trust, and constant organizational change". Notably in his view, this also introduced "an enhanced

Correspondence to: Norman E. Taylor, Journal of Community Safety and Well Being, Community Safety Knowledge Alliance (CSKA), 111 Research Drive, Suite 105, Saskatoon, SK S7N 3R2.

E-mail: ntaylor@cskacanada.ca 
vision for policing and a commensurate expertise and level of executive leadership necessary to integrate and sustain it" (personal correspondence, October 26, 2017).

\section{LOOKING AROUND TO THE PRESENT}

King's latter observation leads nicely to today. Retired Police Superintendent and Executive Director of the Canadian Association of Chiefs of Police Peter Cuthbert observes that, as he compares his own experience to his son's early career as a second-generation police officer, he sees several fundamental differences in the nature of their core competencies and their life balance expectations. Cuthbert believes that in many ways, these differences are framed by stark changes in the socioeconomic position that police members now hold, the complex nature of the services they are expected to deliver in response to mental health and other social conditions, and the attendant requisites for education and continuing access to and application of research-based evidence and social science (personal correspondence, November 2, 2017). Through advances in technology, new complexities in our globalized economic and social structures, and ably assisted by more than a generation of collective bargaining, today's police members both reflect and enjoy a very different level of professional status, but as one certain result, they also face a much-expanded suite of public expectations, risks, and accountabilities. Continued attention to the safety and well-being of our members must remain a priority in the years ahead.

In this issue of our Journal, Kalyal, Peladeau \& Huey (2017) explore some of these changing requirements as they examine the views and expectations of today's police recruiters. Shipley (2017) considers new challenges for police members and their command teams in coaching and evidence-based learning. Paluck, Banka, McCarron et al. (2017) share in-depth research results that, among other insights, serve to highlight today's complex intersections among criminal justice, mental health, and addictions. And from their recent global examinations into the emerging dimensions of public trust, Clark, Davidson, Hanrahan, et al. (2017) implore Canadian policing to "professionalize relentlessly" and to "embrace accountability", among other considerations.

\section{LOOKING AHEAD TO THE FUTURE}

As of this writing, the government of Ontario has just recently introduced its Safer Ontario Act, proposed legislation that aims to update that province's policing and related systems for the first time in almost 25 years. Reflecting similar developments taking form across the country, Deputy Minister of Community Safety Matthew Torigian (personal communication, November 3, 2017) describes this as "historic changes ... potentially transforming emerging and socially innovative work into the cornerstone of a new law in Ontario", while others have called it "the greatest overhaul of policing in a generation" (Gillis \& Gallant, 2017). The proposed act seeks to support sustainability for First Nations policing, to enhance police accountability, to modernize police roles and service delivery models, and to anchor the future of policing within more collaborative, whole-of-system approaches to community safety and well-being (Ontario Ministry of Community Safety \& Correctional Services, 2017).
Meanwhile in Saskatchewan, similar advances continue to expand in ambition and form as leaders there seek to "signal and support a sustainable culture of collaboration, while also taking decisive steps to reduce institutional and data sharing barriers to advance a new normal" (Dale R. McFee, personal correspondence, November 2, 2017). As we look ahead from a world already transformed by the proliferation of information and communications technologies (ICT), to one with yet untold capacities for data analytics and intelligence-driven responses to community needs and social disorders, we must consider how social equity and consent of the people will remain firm anchor points for policing. Further to her observations on technology's omnipresent advance over the past 50 years, Boniface (2017) also notes, "technology ... can either build public trust or damage it" adding that "I expect or perhaps hope over the next 50 years that policing will re-invent itself. I am not convinced the mandates assigned to policing can remain so broad and numerous in a changing society."

With expanding insights into the social conditions that will affect families and shape communities in the years ahead, it remains vital that policing continues to seek and find its own footing. A further recommendation from Clark et al. (2017) advocates that policing must learn to "relate independently" to harness that critical element cited by King above, wherein community engagement offers the longproven potential to forge trusted and lasting bonds with all members of society.

Looking ahead, Lunney cautions that "the principles of inclusivity and partnership must be sustained and strengthened into the future" (2017). Also in this issue, Nilson reports on promising research that could significantly advance both of these elements by harnessing ICT technologies to expand the reach of collaborative community safety and well-being to all corners of the nation, including those communities most marginalized and often under-serviced by the system as a whole (Nilson, 2017). We find further evidence and momentum for these approaches in the Crofts \& Thomas feature where they introduce Canada as a first-time host of the 2018 International Conference on Law Enforcement and Public Health. Such a partnership may push Canadian policing even further toward its nexus with other public and community-based services, committed together to reducing risk factors while contributing to the essential social determinants of healthy, safe, and just societies (Crofts \& Thomas, 2017).

\section{SERVING AND REFLECTING AN INCLUSIVE SOCIETY}

A society must be inclusive to be truly just. As we look to the next five decades, there is perhaps no more certain projection than the continuation of an ever-diversifying Canada. We are a country where our patterns of immigration derive from all reaches of the globe and are expected to continue as our primary source of growth. We are also a country where growth in our indigenous population is forecast to outpace all others, both on reserve and in urban centres. In the decades ahead, we will most certainly be a country where our ability to embrace inclusion over division may ultimately determine our fate as a nation. 
Commitment to this ideal also requires us to fundamentally re-think the ways that policing and all of our public institutions, serve-or maybe too often fail to serve-the needs of the $51 \%$ of the population that are female. Worthy of examination is an apparent juxtaposition in the message of the recent '\#metoo' social media campaign and the reported frequency of an 'unfounded' designation being assigned to sexual assault complaints, as just one example. Some promising advances are occurring in the way police investigate and respond to crimes most often committed against women, notably the recent national adoption of a framework for addressing intimate partner violence (Gill \& Fitch, 2016), but much more needs to be done across the full spectrum of gender-based crime and victimization.

From race and religion, to gender and gender identity, if we do not get this right inside our own sector, we will not get it right in our service to Canadians.

Further, the complex individual, family, community, and economic impacts endured by all victims of crime will continue to call on us to balance our efforts and ensure that services to victims and reduced impacts from victimization take a higher priority in our overall service delivery mix (Johnson-Way \& O'Sullivan, 2016). As observed by Boniface, technology will create new forms of crime. As victimization from cybercrime inevitably expands and diversifies in the decades ahead, the argument grows stronger for more victim-centred responses, as well as for greater collaboration across the entire public-private system aimed at prevention (CACP Global, 2015).

\section{A FUTURE UNDERWAY}

Says Lunney (2017) in closing his reflections, "I would restate my belief that partnerships developed between the academic community and the police prior to the close of the 20th century were absolutely essential to progress." We can only imagine how much more knowledge we will need to build and share together in the first half of the 21st.

This issue of the Journal features our youngest contributor to date, as 22-year old Brandi co-authors with her father Robert their inter-generational perspectives to the question, "What are we doing to protect newcomer youth in Canada, and help them succeed?" (Chrismas \& Chrismas, 2017). Here is another two-generation policing family potentially in the making, and one that might exemplify the evidence-based policing culture of the future. The younger is completing her undergraduate degree in criminology and hopes to begin a policing career soon after. The older is a 28-year veteran of the Winnipeg Police Service, who just last month earned his $\mathrm{PhD}$ in Peace and Conflict studies.

The younger also offers us some hopeful projections on the next 50 years with, "I think we are growing out of racism and sexism, so that is a good thing. We are not quite there yet, but now police agencies have a larger percentage of female leaders and racism is becoming unacceptable in the public discourse. This, I believe has changed a lot over the past 20 years." At the same time, she cautions that perceptions of police culture among the public may not yet realize on this ideal, and that "mainstream and social media representations of the police hold the potential to enhance or deteriorate those perceptions" (B. Chrismas, personal correspondence, October 17, 2017).

If this young author is correct, we face some important questions. Whatever comes to define our society as a whole in the next half-century, our place within it and our influences upon it are already being formed by the choices we make and the actions we demonstrate today and in the years ahead. Will we chart a determined course? And, are we prepared to guide our own relationship with Canadians-all Canadians?

\section{CONFLICT OF INTEREST DISCLOSURES}

The author declares that there are no conflicts of interest.

\section{AUTHOR AFFILIATIONS}

*Editor-in-Chief, Journal of Community Safety and Well Being.

\section{REFERENCES}

CACP Global (2015). Cybercrime: Police roles and responsibilities within a collaborative framework. Summary report from CACP Executive Global Studies 2015. Kanata, ON: Canadian Association of Chiefs of Police. Retrieved November 4, 2017 from http://www.cacpglobal.ca/images/ pdf/CACPGlobal2015ExecutiveReportCACP.pdf

Chrismas, B. \& Chrismas, R. (2017). What are we doing to protect newcomer youth in Canada, and help them succeed? Journal of Community Safety and Well-being, 2(3), 87-90.

Clark, M., Davidson, R., Hanrahan, V. \& Taylor, N.E. (2017). Public trust in policing: A global search for the genetic code to inform policy and practice in Canada. Journal of Community Safety and Well-being, 2(3), 101-111.

Crofts, N. \& Thomas, S. (2017). Law enforcement and public health: Finding common ground and global solutions to disparities in health and access to criminal justice. Journal of Community Safety and Well-being, 2(3), $74-75$

Gill, C. \& Fitch, L. (2016). Developing and delivering a national framework for collaborative police action to intimate partner violence in Canada. Journal of Community Safety and Well-being, 1(3), 51-55.

Gillis, W. \& Gallant, J. (2017, November 2). Highlights of Ontario's police reforms. Toronto Star. Retrieved November 4, 2017 from https://www. thestar.com/news/gta/2017/11/02/highlights-of-ontarios-policing reforms.html

Johnston Way, S. \& O'Sullivan, S. (2016). Recognizing the role of victim supports in building and maintaining healthy and safe communities. Journal of Community Safety and Well-being, 1(2), 12-15.

Kalyal, H., Peladeau, H. \& Huey, L. (2017). Senior officer and recruiter views on big topics in policing for new recruits. Journal of Community Safety and Well-being, 2(3), 112-115.

Ontario Ministry of Community Safety and Correctional Services (2017) Modernizing Ontario's policing framework, an info-graphic. Toronto, ON Retrieved November 4, 2017 from www.ontario.ca/safercommunities

Nilson, C.R. (2017). Collaborative risk-driven intervention: Research supporting technology-enabled opportunities for upstream virtual services in rura and remote communities. Journal of Community Safety and Well-being, 2(3), $76-86$

Paluck, E., Banka, D. McCarron, M.C.E., \& Pandy, M. (2017). Effectiveness of the Dedicated Substance Abuse Treatment Unit in the Regina Correctional Centre: A seven-year retrospective analysis. Journal of Community Safety and Well-being, 2(3), 91-100.

Shipley, P. (2017). Coaching and evidence-based learning. Journal of Community Safety and Well-being, 2(3), 116-118. 